\title{
LXI. The variation of ionizing power with the velocity of cathode rays
}

\section{J.L. Glasson B.A. B.Sc.}

To cite this article: J.L. Glasson B.A. B.Sc. (1911) LXI. The variation of ionizing power with the velocity of cathode rays, Philosophical Magazine Series 6, 22:130, 647-656, DOI: $10.1080 / 14786441008637160$

To link to this article: http://dx.doi.org/10.1080/14786441008637160

曲 Published online: 20 Apr 2009.

Submit your article to this journal $[\pi$

Џll Article views: 2

Q View related articles $\square$

Citing articles: 10 View citing articles 5 
LXI. The Variation of Ionizing Power with the Velocity of Cathode Rays. $\quad B y$ J. L. Glasson, B.A., B.Sc., 1851 Exhibition Scholar of Adelaide University*.

$\mathbf{I}^{\mathbf{T}}$ $T$ is highly important that we should know the number of ions a cathode ray makes in going unit distance in a gas, and how this number varies with the velocity of the cathode ray. The only experiments which have hitherto been made on this subject are those of Durack. $\mathrm{He}_{e} \dagger$ reached the conclusion that one cathode ray moving with a velocity of $4 \times 10^{9} \mathrm{~cm}$. per. sec. makes 4 pairs of ions per $\mathrm{cm}$. in air at a pressure of $1 \mathrm{~mm}$. of mercury. Later $\ddagger$ using beta rays from radium whose velocity he estimated at $2 \cdot 3$ to $2 \cdot 8 \times 10^{10} \mathrm{~cm}$. per sec. he found that the number of pairs of ions made per $\mathrm{cm}$. in air at $1 \mathrm{~mm}$. pressure was -17. Thus increasing the velocity 6 times has decreased the number of ions produced $2 \frac{1}{2}$ times. However, in both his determinations there are several sources of error. His rays were in neither case homogeneous. In his first series he used the Lenard rays which had come through an aluminium window, and which must bave been fairly completely scattered by it. The beta rays from radium which he used are known to range in velocity from $2 \times 10^{10}$ to nearly $3 \times 10^{10} \mathrm{~cm}$. per second.

Moreover, in neither series did he take any adequate precautions to prevent reflexion of the rays by the electrodes used, nor did he apply any correction factor for this reflexion.

The present experiments were therefore undertaken to eliminate these sources of error.

In order to get a homogeneous bundle of cathode rays of known velocity an apparatus similar to that described by Mr. Whiddington $\$$ was used. $A B$ (fig. 1) represents the section of a solenoid $13 \mathrm{~cm}$. long, wound in 3 layers on a brass tube of $3.70 \mathrm{~cm}$. external diameter. The ends of the tube are flanged and are closed by glass plates waxed on so as to make an air-tight joint. The rays enter the solenoid by a small side tube $\mathrm{E}$ soldered on to the main brass tabe; into $\mathrm{E}$ the discharge tube which is shown at $\mathrm{D}$ is fitted. The rays are deflected through a right angle by the magnetic field and leave the solenoid through a similar exit tube $F$,

- Communicated by Sir J. J. Thomson, F.R.S.

+ Phil. Mag. [6] vol. iv. pp. 29.

t Phil. Mag. [6] vol. v. pp. 550 .

$\$$ Proc. Roy. Soc. July 1911. 
and enter the ionization chamber I. Both the discharge tube and the ionization chamber are waxed on air-tight to the two side tubes of the solenoid with beeswax and resin.

Fig. 1.

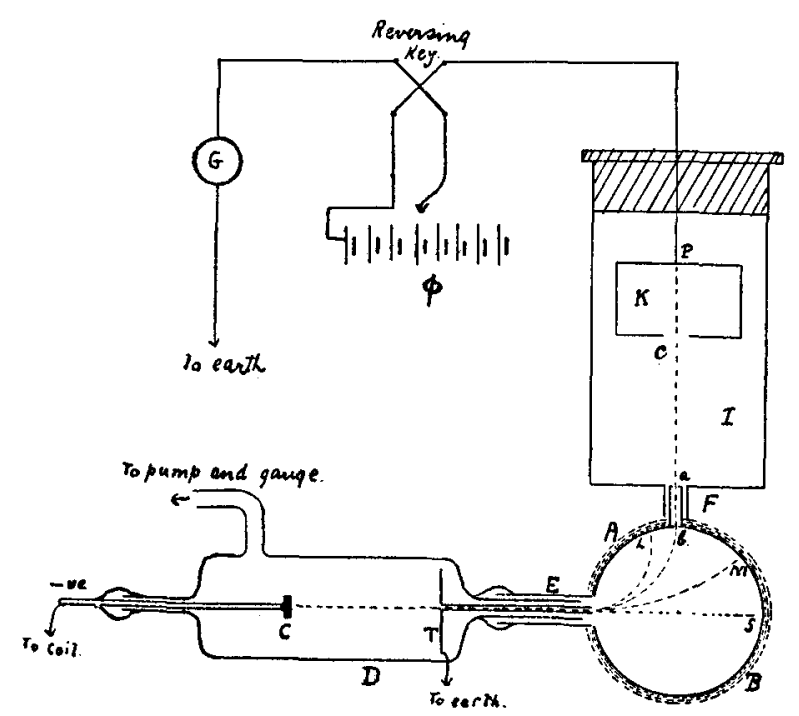

The whole apparatus could be exhausted by a Töpler pump and the pressure could be measured with a McLeod gauge whose constants had been determined before setting up. As soon as the current is passed through the solenoid the rays are bent round and separated into a spectrum as at L M, and by suitably adjusting the current strength rays of any desired velocity may be allowed to fall on the aperture and enter the ionization chamber.

The velocity of the rays which enter the chamber corresponding to any desired current. may easily be calculated when we know the dimensions of the solenoid, the current strength, and the value of $e / m$. The constants of the coil and the calculations are given later.

After resolution into the magnetic spectrum a small pencil of cathode rays of practically uniform velocity enters the jonization chamber through the two diaphragms $a$ and $b$. The hole in each of these was about $\frac{1}{2} \mathrm{~mm}$. in diameter. Having traversed the chamber the rays are caught in an aluminium Faraday cylinder K. The outer brass case of the chamber is earthed while the Faraday cylinder can be raised to a potential sufficient to saturate the gas by a 
small battery of storage-cells $\phi$ whose other terminal is connected through a sensitive Naljer galvanometer to earth.

It is necessary that the rays should cross the chamber in a well defined beam without undergoing appreciable scattering on the way by the gas left in the apparatus. 'lo examine how far this condition is fulfilled a willemite screen was waxed on to the end of the chamber instead of the ebonite plug and Faraday cylinder. A clearly defined spot was obtained showing no signs of scattering at any of the pressures used in the experiments. Its diameter was less than a millimetre; as the opening of the Faraday cylinder was about 4 millimetres in diameter there is no doubt that it caught all the rays.

The Faraday cylinder also does away with any effect due to reflexion of the rays. For of the rays which are reflected on hitting the top of the cylinder only those which come back normally can emerge from it. From the dimensions of the cylinder (which has been drawn to scale in the diagram), it may easily be calculated that the solid angle subtended at the point $\mathrm{P}$ by the aperture is less than one hundredth of the whole solid angle through which we may assume the reflected rays to be distributed. Thus the number which re-emerge is negligible.

The effective length of path of the rays in the chamber is the distance ac. There is no field inside the cylinder and any ions produced by the rays after passing $c$, whether before or after reflexion at $P$, will simply recombine and not affect the current through the chamber.

It is evident that the current through the chamber consists of two parts :-

(1) the current carried by the rays themselves;

(2) the ionization current.

The direction of the former is independent of the sign of the potential applied to the Faraday cylinder while the latter changes in direction when the field is reversed. By such a reversal of the potential of the Faraday cylinder we can thus obtain both the sum and difference of the effects (1) and (2).

Let $n$ be the number of cathode rays crossing the chamber per second, and $a$ the number of pairs of ions made by one eathode ray in going $1 \mathrm{~cm}$. in air at a pressure of $1 \mathrm{~mm}$. of mercury, and let $l$ be the length of path of the rays in the chamber.

Then the current carried by the rays $=n e$.

The saturation current carried by the ions $=$ nalpe. 
Thus when the Faraday cylinder is positively charged the current is given by

$$
\mathrm{C}_{1}=\text { ne+nalpe, }
$$

and when the cylinder is negative,

$$
\mathrm{C}_{2}^{\prime}=n e-n a l p e .
$$

Thus,

$$
\frac{\mathrm{C}_{1}-\mathrm{C}_{2}}{\mathrm{C}_{1}+\mathrm{C}_{2}}=\alpha l p(=\mathrm{N}) \text {. }
$$

It will be convenient to denote this ratio by $\mathrm{N}$; it is evidently the number of pairs of ions made by a ray in crossing the chamber.

From the ratio $\mathbf{N}$ knowing $l$ and $p$ we can at once determine $a$ or the specific ionization produced by a cathode ray.

At pressures such as thase used here ionization by collision comes in for comparatively low field strengths and there is some difficulty in determining the correct voltage to apply to the gas in order to obtain saturation. One of the curves connecting $\frac{C_{1}-C_{2}}{U_{1}+C_{2}}(=N)$ with voltage is shown in fig. 2 .

Fig. 2.

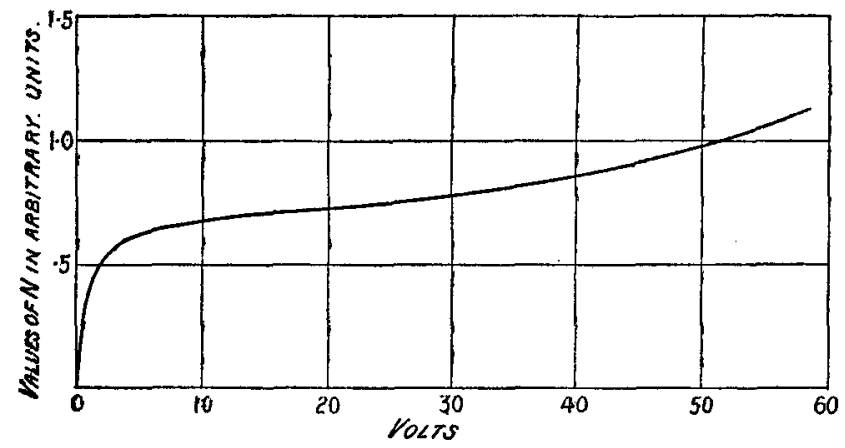

It will be seen that ionization by collision comes in almost as soon as saturation is obtained. In these experiments a potential of 6 volts was applied to the cylinder.

\section{Results.}

The method of taking the readings is as follows. The apparatus was exhausted down to a pressure at which the cathode rays begin to be produced. The current through 
the solenoid was adjusted by resistances to a definite value indicated by a Weston ammeter and the values of $\mathrm{C}_{1}$ and $\mathrm{C}_{2}$ observed on the galvanometer scale. The solenoid current was then altered so as to cause a different part of the spectrum to enter the chamber and the galvanometer deflexions again read. Readings were taken in this way throughout the range of the spectrum. 'l'he pressure was then altered and a fresh set of readings taken over the range of velocities obtained.

In practice, the range of velocities which can be used is limited both at its lower and upper ends. The velocity of the rays produced by the discharge depends on the pressure in the tube. The highest pressure al which cathode rays appear at $s$ was found to be $.21 \mathrm{~mm}$. of $\mathrm{Hg}$. It was found that the slowest rays produced at this pressure had a velocity corresponding to 6 amperes, i.e. it required a current of 6 amperes in the solenoid to deflect them into the ionization chamber. The upper limit to the velocities employable is governed by the following considerations. To produce fast rays the pressure in the apparatus must be reduced and consequently the number of ions produced by a ray in crossing the chamber is also reduced. Now theoretically the most accurate values of $\frac{\mathrm{C}_{1}-\mathrm{C}_{2}}{\mathrm{C}_{1}+\mathrm{C}_{2}}(=\mathrm{N})$ are obtained when the difference between $\mathrm{C}_{1}$ and $\mathrm{C}_{2}$ is as great as possible. For small errors in reading both $\mathrm{C}_{1}$ and $\mathrm{C}_{2}$ produce a much greater proportionate error in their difference. So that when $\mathrm{C}_{1}-\mathrm{C}_{2}$ is small the liability to error in the value of $\mathrm{N}$ is very great. Although a few readings were taken with a low pressure and velocities corresponding to 10 or 11 amperes they were discarded for the above reasons and no readings are given for velocities greater than 9 amperes.

The results of the experiments in air are shown in Table $I$. Column 1 . gives the pressure in the apparatus in readings of the McLeod gauge; column II. gives the current flowing through the solenoid in amperes; column III. the mean values of the ratio $\frac{\mathrm{C}_{1}-\mathrm{C}_{2}}{\mathrm{C}_{1}+\mathrm{C}_{2}}$, i.e. the actual number of ions made by a ray in traversing the chamber.

In fig. 3 (p. 653) the values of $\mathrm{N}$ have been plotted against the pressure in the tube for different velocities of rays. It is evident that the number of ions made should be proportional to the pressure in the tube and the curves connecting the two should be straight lines passing through the origin of coordinates. The curves in fig. 3 have been obtained by 
joining the origin to the centroids of each set of points. It will be seen that the points fit the curves fairly well.

TABLE I.

\begin{tabular}{|c|c|c|c|}
\hline $\begin{array}{c}\text { I. } \\
\text { Preesure in } \\
\mathrm{mm} . \times 900 \text {. }\end{array}$ & $\begin{array}{c}\text { II. } \\
\text { Current in } \\
\text { solenoid (amps.) }\end{array}$ & $\begin{array}{c}\text { III. } \\
\frac{\mathrm{C}_{1}-\mathrm{C}_{2}}{\mathrm{C}_{1}+\mathrm{C}_{2}}=\mathrm{N}\end{array}$ & $\begin{array}{c}18 . \\
\mathrm{N} \\
x \times y \cup 0\end{array}$ \\
\hline 190 & $\begin{array}{l}6 \\
65 \\
7 \\
7.5\end{array}$ & $\begin{array}{r}1.26 \\
1.09 \\
.97 \\
.86\end{array}$ & $\begin{array}{r}-0066 \\
57 \\
51 \\
45\end{array}$ \\
\hline 175 & $\begin{array}{l}6 \\
6 \cdot 5 \\
7 \\
7 \cdot 5\end{array}$ & $\begin{array}{r}1 \cdot 17 \\
1 \cdot 01 \\
\cdot 90 \\
\cdot 80\end{array}$ & $\begin{array}{r}0067 \\
58 \\
51 \\
46\end{array}$ \\
\hline 140 & $\begin{array}{l}6 \\
655 \\
7 \\
7 \cdot 5 \\
8\end{array}$ & $\begin{array}{l}.94 \\
.81 \\
.72 \\
.64 \\
.58\end{array}$ & $\begin{array}{r}0067 \\
58 \\
51 \\
46 \\
41\end{array}$ \\
\hline 105 & $\begin{array}{l}7 \\
7 \cdot 5 \\
8 \\
8 \cdot 5 \\
9\end{array}$ & $\begin{array}{l}-73 \\
48 \\
-44 \\
-40 \\
.35\end{array}$ & $\begin{array}{r}0050 \\
46 \\
4 \pm \\
38 \\
38 \\
33\end{array}$ \\
\hline 90 & $\begin{array}{l}7 \\
7 \cdot 5 \\
8 \\
8 \cdot 5 \\
9\end{array}$ & $\begin{array}{l}.47 \\
.42 \\
\cdot 38 \\
-34 \\
.30\end{array}$ & $\begin{array}{r}-00.52 \\
47 \\
42 \\
38 \\
33\end{array}$ \\
\hline 75 & $\begin{array}{l}8 \\
8 \cdot 5 \\
9\end{array}$ & $\begin{array}{l}\cdot 32 \\
-28 \\
\cdot 25\end{array}$ & $\begin{array}{r}0043 \\
37 \\
33\end{array}$ \\
\hline
\end{tabular}

In order to plot the variation of ionization with velocity of the cathode rays, the values of $\mathrm{N}$ given in Table $\bar{I}$. column III. have been reduced to a standard pressure by dividing the numbers in column III. by those in column I. It will be seen that the numbers obtained for each of the different velocities of rays agree to within about 4 per cent. To get the most probable value the means have been taken, and these are entered in Table II., column III. (p. 654) against the corresponding velocity in column I. 
Power with the Velocity of Cathode Rays.

Fig. 3.

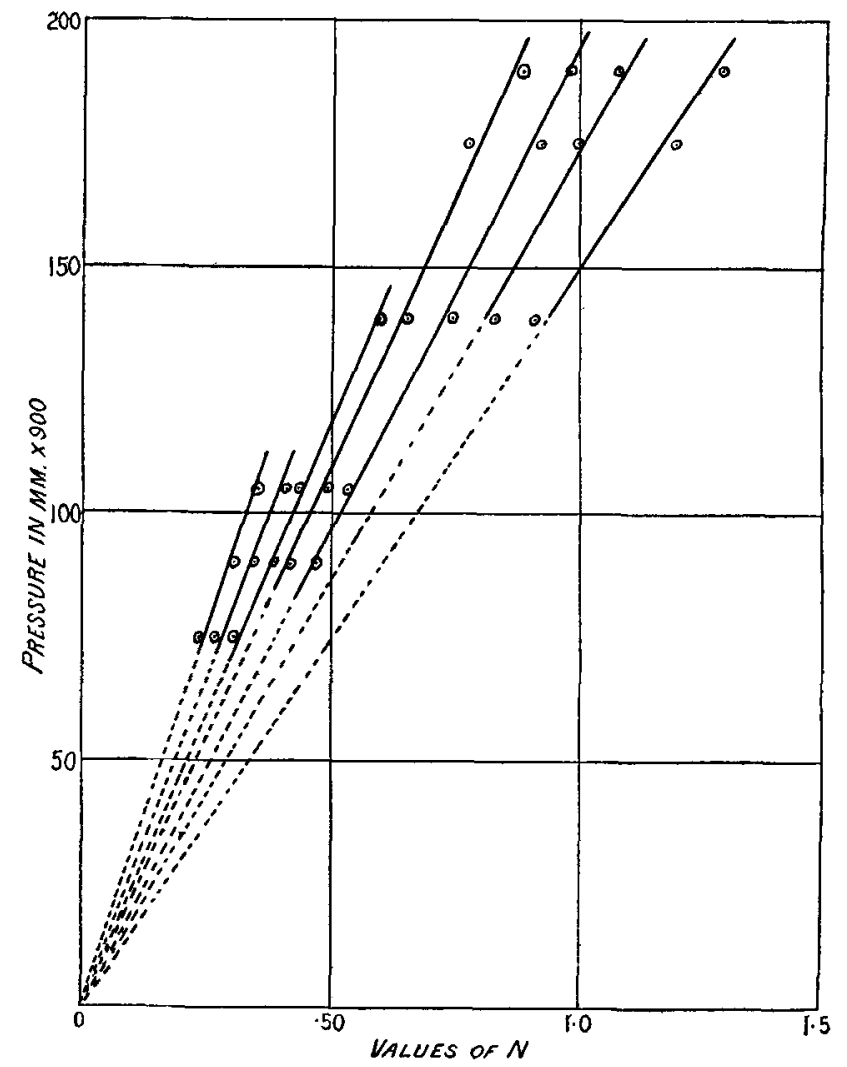

The numbers in column II. give the velocity of the rays in $\mathrm{cm} . \div 10^{\circ}$ per sec.; those in column IV. give the absolute values of $\alpha$ corresponding to the values of $\frac{\mathrm{N}}{\mathrm{P} \times 900}$ in column III. The method of calculating these columns is given later.

In fig. 4, curve I., the figures in column IV. have been plotted against those in column 1I. This curve represents therefore the variation of specific ionization with the velocity of the rays.

In the same figure have been plotted the curves which would have been obtained if the ionization had been inversely proportional to the first and second powers of the velocity. These are shown in curves II. and III. respectively.

It seems in this region the rate of variation is intermediate 
654 Mr. J. L. Glasson on the Variation of Ionizing

TABIE II.

\begin{tabular}{|c|c|c|c|}
\hline $\begin{array}{l}\text { I. } \\
\text { Velocity of rays } \\
\text { in smperes. }\end{array}$ & $\begin{array}{l}\text { II. } \\
\text { Velocity in } \\
\text { cm. } \times 10-9 \text {. }\end{array}$ & $\begin{array}{l}111 . \\
\frac{N}{P \times 900}\end{array}$ & $\begin{array}{c}\text { IV. } \\
\text { Values of } a .\end{array}$ \\
\hline 6 & 4.08 & .0067 & $2 \cdot 01$ \\
\hline 6.5 & $4 \cdot 12$ & .00575 & 1.72 \\
\hline 7 & $4 \cdot 76$ & .0051 & 1.53 \\
\hline 7.5 & $5 \cdot 10$ & .0046 & $1 \cdot 33$ \\
\hline 8 & $5 \cdot 44$ & .0042 & 1.26 \\
\hline $8 \cdot 5$ & $5 \cdot 78$ & .00375 & $1 \cdot 12$ \\
\hline 9 & $6 \cdot 12$ & .0033 & .99 \\
\hline
\end{tabular}

Fig. 4.

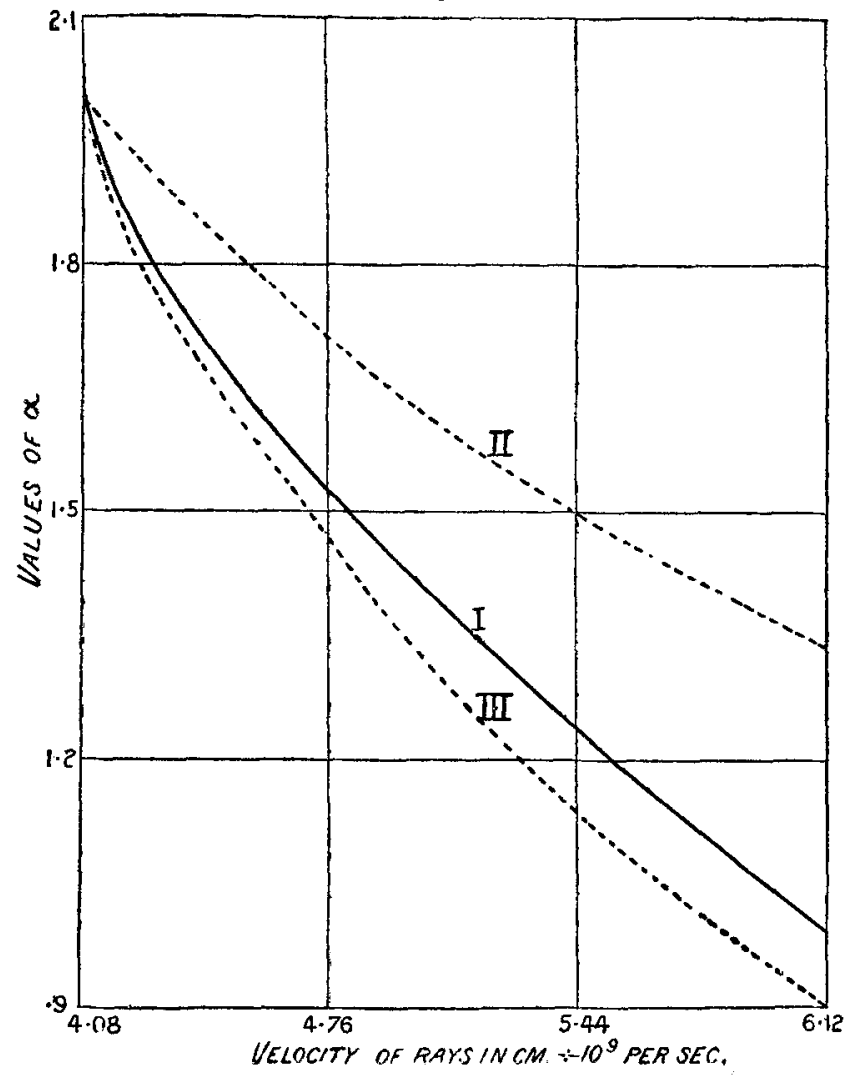


between an inverse first-power and an inverse second-power law and is much nearer to the latter than to the former.

Calculation of the absolute number of ions made by a Cathode Ray of known velocity.

Hitherto the values given for the number of ions and the velocity of the rays have been purely relative. It is important to get some definite numerical estimate of the specific ionization made in air by a cathode ray of known velocity.

The dimensions of the solenoid were as follows :-

Internal diameter of windings $\ldots \ldots \ldots \ldots=3 \cdot 70 \mathrm{~cm}$.

External diameter of windings.......... $=4.65$,

Total number of turns in the three layers $=231$

Total length of solenoid .............. $=13.0 \mathrm{~cm}$.

The calculated value of the field at the centre obtained by summing the magnetic force at the centre due to each turn over the whole length of the solenoid gives a value of $\mathrm{H}=20.8$ gauss per ampere. The field strength was tested experimentally with a small search-coil and a ballistic galvanometer, each of which had been previously standardized. With 5 amperes flowing through the solenoid the field strength was found to be 109 gauss at the centre and 105 gauss at the sides. This gives as a mean 107 gauss or 21.4 gauss per ampere. This differs from the calculated value by less than 3 per cent., which is satisfactory in view of the roughness of the winding and the degree of accuracy obtainable in the rest of the measurements. We may take the value of $H$ to be 21 gauss per ampere-a mean of the calculated and experimental values.

The radius of the cirele into which the rays are bent to enter the aperture is equal to the internal radius of the tube which was $1.77 \mathrm{~cm}$. From the formula $\rho=\frac{m v}{e \bar{H}}$ we find the velocity of the rays is $6 \cdot 8 \times 10^{8} \times \mathrm{C}$ where $\mathrm{C}$ is the solenoid current in amperes.

The readings obtained for $\mathrm{N}$ are considered to be most accurate when the current in the solenoid was 7 amperes. For then the number of cathode rays was large and also the difference between $\mathrm{C}_{1}$ and $\mathrm{C}_{2}$ was fairly great. From column III. of Table II. the mean value of $\frac{\mathrm{N}}{\mathrm{P} \times \overline{900}}$ for
7 amperes is 0051 .

$$
\text { Now } \quad \alpha=\frac{\mathrm{N}}{\mathrm{P} l} \text {. }
$$

In all these experiments the leugth $l$ was $3.00 \mathrm{~cm}$. So that $\alpha=1.53$. 
Therefore 1 cathode ray moving with a velocity of $7 \times 6.8 \times 10^{8}=4.8 \times 10^{9} \mathrm{~cm}$. per sec. makes 1.5 pairs of ions in going $1 \mathrm{~cm}$. in air at a pressure of $1 \mathrm{~mm}$. of $\mathrm{Hg}$.

It is interesting to compare this value with that obtained by Durack. He found that 1 cathode ray moving with a velocity of $4 \times 10^{9} \mathrm{~cm}$. per sec. makes 43 pairs of ions per $\mathrm{cm}$. In the light of more recent experiments, his determination of the velocity may be corrected. In applying the formula $v=\mathrm{H} \frac{e}{m} \frac{d^{2}+\delta}{2 \delta}$ to determine the velocity from the magnetic deflexion, he made $\frac{e}{m}=10^{7}$ instead of the more correct value $1.8 \times 10^{7}$. This would make the velocity of his rays $7 \cdot 2 \times 10^{9} \mathrm{~cm}$. per sec. Assuming that the iomization varies inversely as the square of the velocity, for a velocity of $11.8 \times 10^{9} \mathrm{~cm}$. per sec. we get $\alpha=\cdot 97$. The value obtained in these experiments was 1.5 . The agreement is as good as might be expected.

I desire to thank Sir J. J. Thomson for his inspiring interest and advice in these experiments.

Caius College,

July $20,1911$.

LXII. The Mode of C'onduction in Gases.

To the Editors of the Philosophical Magazine.

Gentlemen,-

$T N$ a paper on "The Mode of Conduction in Gases illus1 trated by the Behaviour of Electric Vacuum Tubes" that appeared in the July Number of the Philosophical Magazine, Sir Oliver Lodge has put forward a theory to explain how the conductivity is produced. A good many theories of these phenomena have been proposed which are in some points consistent and founded on experimental evidence, but there are few in which so many imaginary properties are attributed to the molecules. To mention an instance the following passage may be quoted. "In an active vacuum-tube the continual presence of such ions near the cathode depends on their having been able to travel from the anode; nevertheless they are not atoms of the anode itself, but are gas atoms which have become positively charged by contact with it,-each of them having presumably given up an electron to the metal.

"It is at the surface of the anode therefore that the separation of electricities really takes place, under stress of the applied E.M.F. The ions then migrate to the cathode, and 